de dentes, manequins ganhavam vida, escadas e portas se tornavam grandes obstáculos”, lembra Quadros. Para ela, esse era o maior talento da construção visual de Chaplin: a ressignificação das coisas, que confere plasticidade à sua produção cinematográfica e corrobora a narrativa de que ele estaria sempre à margem. "É como se os objetos desfrutassem da mesma liberdade do vagabundo Carlitos. Isso resume seu principal talento, ou seja, algo característico da personagem evolui para a forma como ele se relaciona com o ambiente e com a cena em si, estabelecendo aí uma linguagem única em seus filmes, criando a linguagem cinematográfica chapliana", acredita a pesquisadora.

Com uma obra tão extensa e diversa, qual seria o melhor filme de Chaplin? Para Quadros, "Chaplin é um cineasta que se constrói com a obra inteira”. Mesmo assim, ela aponta Twenty minutes of love (1914), Luzes da cidade (1931) e Luzes da ribalta (1952) como os seus preferidos. "São escolhas que representam o melhor de todas as fases da carreira de Chaplin: o começo, com a experimentação da técnica; o meio, em que ele já teria atingido um domínio maior sobre seu estilo; e o final, em que ele revê diversos aspectos de sua vida", explica.

As comemorações dos 130 anos de Chaplin são uma oportunidade para impulsionar novos olhares e descobertas em torno desse incrível legado. "Acredito que é sempre importante exibir os filmes de Chaplin e discuti-los depois, criando assim, um olhar contemporâneo para a sua obra”, finaliza Quadros.

Amando Martinelli

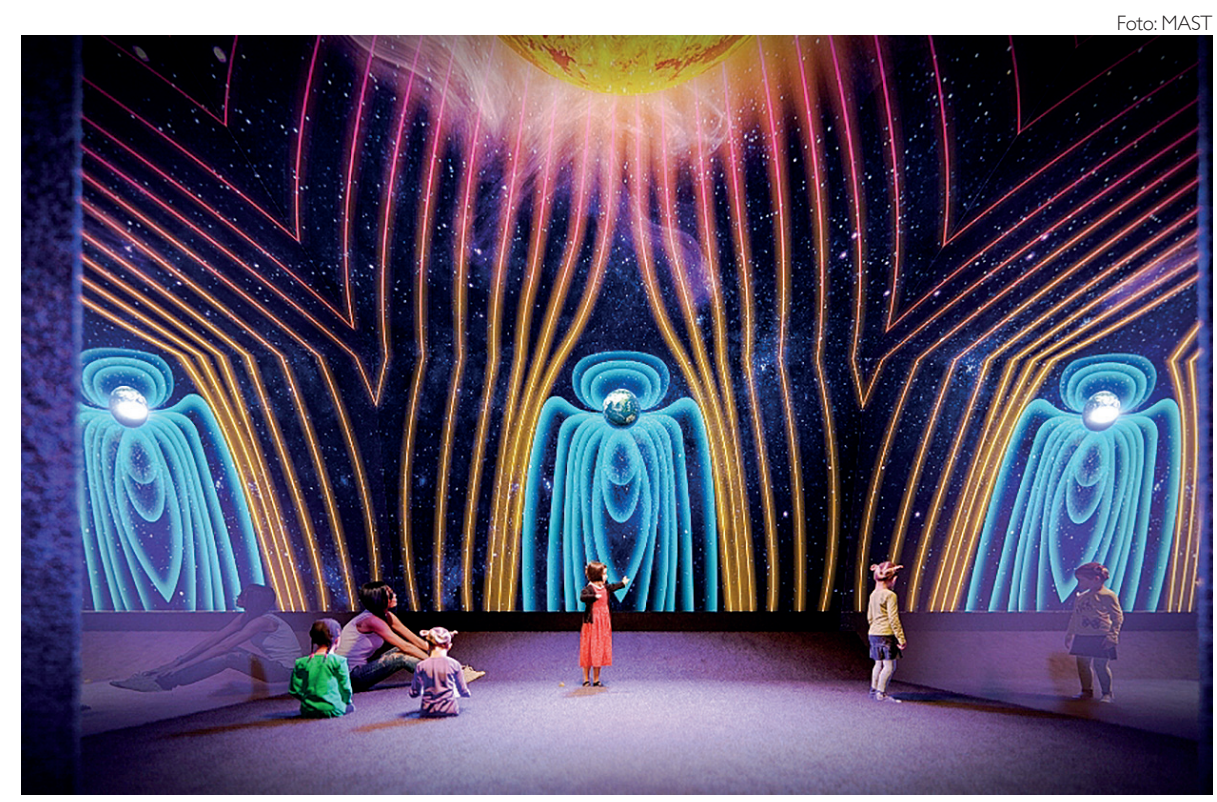

Centro de visitantes do MAST, instituição que tem investido em ações de divulgação da astronomia

EDUCAÇÃO

\title{
A DIVULGAÇÃO CIENTÍFICA DA ASTRONOMIA NO BRASIL
}

O céu fascina o homem há milhares de anos. Tanto que a astronomia é considerada a mais antiga das ciências-seus primeiros registros datam de 3.000 a.C. e se devem aos chineses, babilônios, assírios e egípcios. Ao longo de todo esse tempo, a astronomia vem guiando o homem rumo ao avanço científico. A astronomia brasileira também tem uma longa história. O Brasil abrigou o primeiro observatório astronômico do Hemisfério Sul, construído em 1639 no palácio Friburgo, em Recife, pelos holandeses. $\mathrm{O} \mathrm{Ob}$ servatório Nacional, originalmente denominado Imperial Observatório do Rio de Janeiro, foi criado em
1827, e é uma das mais antigas instituiçôes científicas brasileiras. No seu primeiro século de existência, o Observatório Nacional organizou e participou de diversas expedições científicas de astronomia. A mais famosa delas foi a do eclipse solar de Sobral (CE), em 1919, que ajudou a confirmar a teoria da relatividade geral de Einsten.

Aliás, neste ano comemoram-se os cem anos do evento, com direito ao Núcleo Temático dedicado ao tema nesta edição da Ciênciad Cultura, exposição cultural e encontro internacional organizado pela Sociedade Brasileira para o Progresso da Ciência (SBPC) no mês de maio. $\mathrm{O}$ fa- 
moso eclipse, observado na pequena cidade do interior cearense, causou tanto alvoroço porque confirmou a teoria da relatividade formulada por Albert Einstein. A equipe inglesa, liderada pelo astrônomo inglês Arthur Eddington, da Royal Astronomical Society, tirou várias fotografias durante o eclipse que comprovaram que a luz se desvia ao passar próxima a um corpo celeste de grande massa. Para celebrar o centenário, a SBPC, em parceria com a prefeitura de Sobral e com o governo do estado do Ceará, organizou o Encontro Internacional do Centenário do Eclipse de Sobral (1919-2019), que aconteceu nos dias 28 a 30 de maio, com palestras, bate-papos, e apresentações culturais. Também o Museu de Astronomia e Ciências Afins (MAST), em parceria com o Observatório Nacional, inaugurou no dia 29 de maio a exposição O eclipse - Einstein, Sobral e o GPS. Apesar de seu longo histórico no que se refere à divulgação científica da astronomia, o Brasil ainda tem um longo caminho a percorrer. "Em geral os jornais e as mídias fazem traduções de pautas internacionais, o que resulta em invisibilidade do que é produzido no Brasil", aponta a física Daniela Borges Pavani, professora do Departamento de Astronomia da Universidade Federal do Rio Grande do Sul (UFRGS).

Esse não é o único problema enfrentado pela área. A falta de preparo dos profissionais da mídia, de investimento (e até mesmo de interesse) por parte dos veículos de comunicação e de acessibilidade dos cientistas também dificulta - e muito - a divulgação científica da astronomia brasileira. "A divulgação científica de astronomia é uma via de mão dupla”, explica o físico Roberto Dias da Costa, professor do Departamento de Astronomia da Universidade de São Paulo (USP). "Por um lado, é necessário que os órgãos de imprensa se interessem pelo tema, quebrando aquele paradigma de que apenas política, polícia e economia interessam ao público. Por outro, os astrônomos profissionais necessitam tornar-se acessíveis à imprensa, tanto em termos de disponibilidade de tempo como em termos de comunicabilidade".

Buscando favorecer a divulgação da área, a Sociedade Astronômica Brasileira (SAB) tem feito um esforço para disponibilizar pesquisadores $\mathrm{da}$ área como contatos para a imprensa. Além disso a SAB oferece aos influenciadores digitais, em especial aos youtubers, um programa de tutoria, em que astrofísicos dão apoio para a divulgação científica da área.
EdUCAÇÃo \& ASTRONOMIA Para além da divulgação, a educação pela astronomia também se faz extremamente importante. Por envolver uma combinação de ciência, tecnologia e cultura, a astronomia é um instrumento poderoso para despertar o interesse e envolver os jovens estudantes nas diferentes áreas da ciência.

Nos parâmetros curriculares nacionais (PCN), que já completam 30 anos, ou na base comum curricular nacional (BCCN), proposta mais recentemente, a astronomia é apontada como uma aliada importante na introdução de novas práticas pedagógicas e como uma área do conhecimento transversal. "A astronomia não é uma disciplina escolar, mas ela é multidisciplinar, possibilitando discutir temas da geografia, física, história, artes...”, explica o físico Gustavo Rojas, pesquisador do Núcleo de Formação de Professores da Universidade Federal de São Carlos (UFSCar) e líder das equipes brasileiras que disputam a

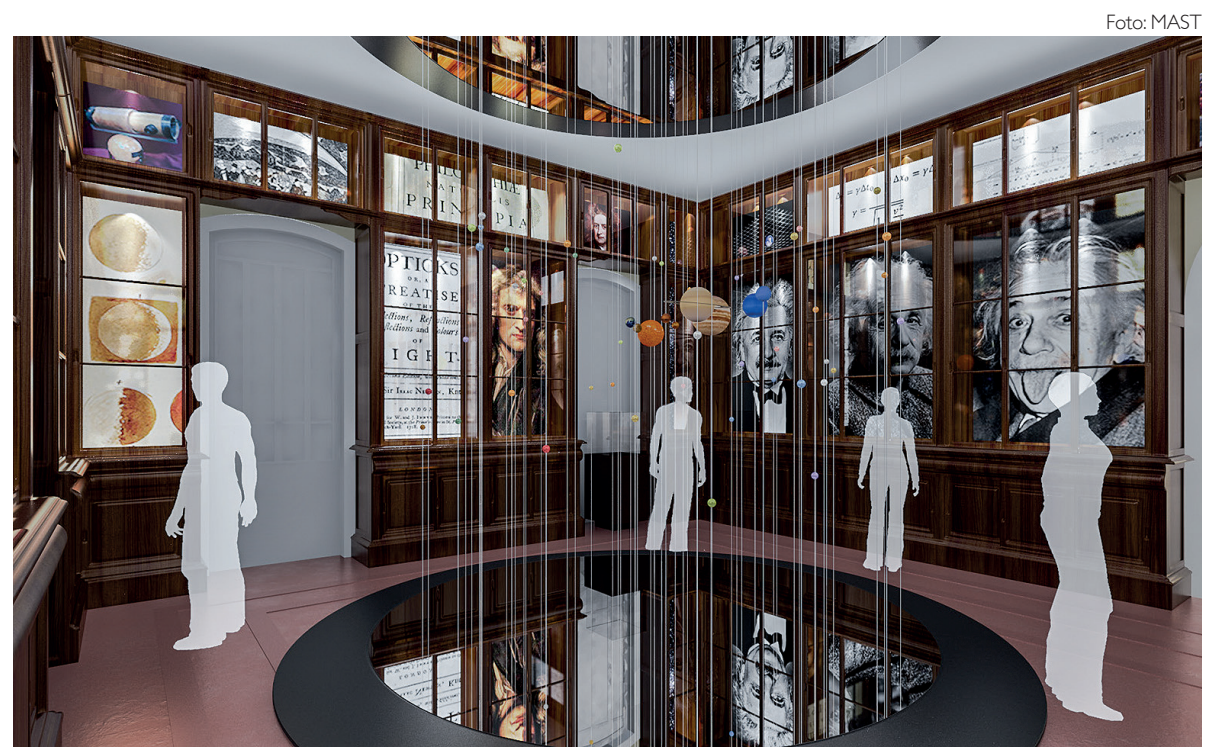

Um dos ambientes da exposição organizada pelo MAST sobre o eclipse de Sobral 
Olimpíada Internacional de Astronomia e Astrofísica (IOAA).

No Brasil, a falta de investimento para a preparação dos professores ainda é um problema frequente. Isso faz com que o tema seja abordado de forma inadequada, ou até mesmo não seja abordado, em sala de aula. No entanto, algumas iniciativas vêm buscando preencher essa lacuna. A USP oferece cursos a distância para professores, como o mestrado profissional em ensino de astronomia, criado em 2013. Uma das iniciativas mais exemplares em relação aos estudantes é a Olimpíada Brasileira de Astronomia e Astronáutica (OBA), um evento nacional realizado nas escolas brasileiras desde 1998 pela SAB, que atualmente atinge mais de um milhão de estudantes do ensino fundamental e médio. "Além dessas ações, espaços como planetários, observatórios e museus de ciências são importantes para educar e divulgar a astronomia. E, nesse processo, falar e entender a ciência e suas implicações em nossas vidas é fundamental", afirma Rojas.

O BRASIL E 0 MUNDO A exploração do espaço aumentou não apenas nosso conhecimento sobre o universo, mas também trouxe vários benefícios para nossa vida na Terra. Os resultados do desenvolvimento científico e tecnológico da astronomia frequentemente se transformam em aplicações essenciais para o nosso dia a dia. Telecomunicações, GPS, previsões meteorológicas, painéis solares, scanners de ressonância magnética e muitas outras aplicações para a medicina são apenas algumas das áreas dependentes da infraestrutura espacial. "É comum as pessoas pensarem que pesquisar assuntos que não têm aplicação prática imediata é perda de tempo. Porém, a pesquisa bási$\mathrm{ca}$, entre as quais está a astronomia, é propulsora do desenvolvimento científico-tecnológico e social", explica Pavani. "Em maio comemoramos 100 anos da comprovação da teoria da relatividade geral, assunto em que o Brasil foi protagonista através das observações do eclipse total do Sol em Sobral (CE). Um assunto que parece totalmente desconectado da nossa vida cotidiana. Entretanto, não poderíamos usar esses aplicativos de chamar táxi, Uber etc. porque o funcionamento do GPS, que está por trás desses serviços, baseia-se nessa teoria. Temos inúmeros exemplos, que vão da medicina ao Wi-Fi”, diz a professora da UFRGS.

E apesar de todas as dificuldades, o Brasil faz parte da expansão desse tipo de conhecimento. Nos últimos anos, a quantidade de artigos científicos na área publicados por brasileiros cresceu significativamente, passando de quatro mil pesquisas divulgadas, entre 2000 e 2009 , para 5,3 mil, de 2010 a 2017. E não é só, nosso país também faz parte de iniciativas internacionais, como o Bingo, um radiotelescópio projetado para fazer a primeira detecção de oscilações acústicas de Byron (BAO). Por meio desse telescópio será possível medir as propriedades da energia escura. O projeto está sendo construído pelo Brasil e inclui pesquisadores da Arábia Saudita, Suíça, Reino Unido e Uruguai.
Claro que há alguns percalços no caminho do desenvolvimento dessa área por aqui. Por anos o país lutou para participar do Observatório Europeu do Sul (ESO). Em 2010, a ESO aprovou a entrada do Brasil no consórcio, mas apenas em 2015 o Congresso brasileiro aprovou a adesão. Apesar do processo ainda depender da sanção presidencial, a ESO fez um acordo de adesão que colocava o Brasil em condiçãao de igualdade com os outros 14 membros. Isso possibilitava que as indústrias brasileiras participassem nas apresentações das propostas do Observatório e que os astrônomos de instituições brasileiras concorressem a tempo de observação nos telescópios do ESO nas mesmas condições que os demais membros. Porém, o não cumprimento da oficialização do país como participante e a falta do acerto das obrigações financeiras previstas obrigaram o ESO a suspender a participação brasileira no ano passado. "Uma sociedade bem informada - tanto em sua educação escolar como em sua educação científica - é essencial para a tomada de decisões. De modo que em episódios de restrições orçamentárias o cidadão possa avaliar a situação criticamente e enxergar que esses campos (a educação e a ciência) são essenciais, percebendo que não existe país desenvolvido e com justiça social sem investimento em educação e que a ciência é uma peça-chave no desenvolvimento econômico", afirma Rojas. 